\title{
Les Spirales du sens chez Renaud Camus, textes réunis par Ralph Sarkonak
}

\section{Enrico Bonadei}

\section{(2) OpenEdition}

1 Journals

\section{Edizione digitale}

URL: http://journals.openedition.org/studifrancesi/7037

DOI: ERREUR PDO dans/localdata/www-bin/Core/Core/Db/Db.class.php L.34 : SQLSTATE[HYO00]

[2006] MySQL server has gone away

ISSN: 2421-5856

\section{Editore}

Rosenberg \& Sellier

\section{Edizione cartacea}

Data di pubblicazione: 1 septembre 2010

Paginazione: 408-409

ISSN: 0039-2944

\section{Notizia bibliografica digitale}

Enrico Bonadei, «Les Spirales du sens chez Renaud Camus, textes réunis par Ralph Sarkonak», Studi Francesi [Online], 161 (LIV | II) | 2010, online dal 30 novembre 2015, consultato il 07 janvier 2021. URL: http://journals.openedition.org/studifrancesi/7037 ; DOI: https://doi.org/10.4000/studifrancesi.7037

Questo documento è stato generato automaticamente il 7 janvier 2021.

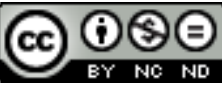

Studi Francesi è distribuita con Licenza Creative Commons Attribuzione - Non commerciale - Non opere derivate 4.0 Internazionale. 


\title{
Les Spirales du sens chez Renaud Camus, textes réunis par Ralph Sarkonak
}

\author{
Enrico Bonadei
}

\section{NOTIZIA}

Les Spirales du sens chez Renaud Camus, textes réunis par Ralph SARKONAK, AmsterdamNew York, Rodopi, 2009 («Faux Titre», 336), pp. 290.

1 La raccolta è imperniata su tre temi in particolare: l'ansia autobiografica di Renaud Camus, la sua diffidenza rispetto ad ogni chiara affermazione di senso, le accuse di razzismo e antisemitismo che nel 2000 ne portarono il nome sotto i riflettori della cronaca. I primi due punti, e qualcun'altra delle molteplici tematiche affrontate nell'opera dello scrittore testimoniano un'eterogeneità di approcci ed opinioni ricca e stimolante, inevitabile nei riguardi di un autore capace di prese di posizione provocatorie e scandalose, come anche di ambigue ritrattazioni al limite della contraddizione, e a volte ben oltre. Riguardo all'affaire Camus, invece, l'omogeneità degli interventi pro-camusiani offre una visione ridotta e parziale del caso, dando per scontata la diffusione di un pregiudizio anti-camusiano, in realtà non accertato. Il volume riesce comunque nell'impresa tutt'altro che facile di dare un'idea «de l'œuvre multiforme de Renaud Camus, laquelle comprend maintenant plus de soixante-dix livres, sans parler des sites de l'auteur, dont Vaisseux brûlés et celui du parti de l'innocence» (p. 12).

2 Nell'introduzione di Ralph SARKonAK, Renaud Camus, “wordsmith” à l'œeuvre (pp. 11-24), si pone l'accento sull'importanza di diari e autobiografia nell'opera di Camus, oltre che sul carattere nostalgico e malinconico di questo provocatore reazionario, definito «le Saniette de la France du Xxiee siècle» (p. 14). 

paesaggista «en deuil des paysages de France» (p. 26), al quale si offrono tre possibili reazioni, complementari e alternative: abbandonarsi ad una polemica malinconica o compiaciuta, fare tesoro di ciò che resiste, oppure partire verso luoghi meno corrotti.

Ritorna quindi Ralph SARKONAK con La Chute dans la folie (pp. 41-67), in cui sono sottilmente dettagliati i diversi tipi di follia descritti e raccontati in Roman roi e Roman furieux.

Catherine RANNOUX, in Renaud Camus, remarqueur mélancolique (pp. 69-105), saggia le doti di linguista espresse dallo scrittore in Répertoire des délicatesses du français contemporain. Il suo bilancio non manca di finezza e severità.

Charles PORTER (À la recherche de l'autobiographie, pp. 107-138) porta al centro della raccolta l'esplorazione autobiografica che Camus dispiega attraverso numerose forme letterarie: diari e agende, autobiografie e romanzi autobiografici.

7 La domanda cui Thomas CLERC si propone di rispondere è chiara fin dal titolo: Le Journal de Renaud Camus est-il bathmologique? (pp. 139-165). Emergono così le divergenze tra due modi di intendere la bathmologia barthesiana, secondo lo studioso e secondo lo scrittore, senza che quest'ultimo veda vilipesa la propria posizione di «réactionnaire de charme» (p. 164).

In “Flatters", peintre et psychagogue (pp. 167-206), Paul LÉoN rivela l'importanza, indaga l'influenza, illustra la presenza di Jean-Paul Marcheschi nell'opera dell'amico e confidente, mentre Hugo FREY, in Contradictions Without End (pp. 207-230), ripercorre nascita e diffusione del Parti de l'in-nocence, fondato dallo scrittore nel 2002. Lo studioso mette in luce in particolare le debolezze del progetto politico e letterario, evidenti nel contraddittorio rapporto con internet - che Camus disprezza e al contempo sfrutta largamente-e nel rischio di «overload and boredom» (p. 230) prodotto dalla pubblicazione istantanea e copiosa offerta dalla rete.

9 Chiudono la raccolta tre interviste realizzate da Ralph SARKONAK, incentrate sull'affaire Camus. Il curatore della raccolta rivolge le sue domande a Charles Porter, organizzatore insieme a Jan Baetens del convegno Renaud Camus, écrivain, svoltosi a Yale nel 2000 e investito dalla portata inaspettata dello scandalo. Seguono le conversazioni con Bruno Chaouat e Alain Finkielkraut, difensori di Camus. 